\title{
Ocean Science as a Bridge
}

Kenneth Brink

T

his issue of Oceanography acknowledges the life, science and legacy of Akiro Okubo. It is certainly fitting to pay tribute to this scientist who influenced a range of oceanographic disciplines with his remarkable research. Okubo's life presents to us a model of doing science effectively, as well as lessons for how oceanography operates on a global basis.

Oceanography is driven by a proudly cosmopolitan community. Many of us have close friends from nations other than our own, and in many cases those friendships were initiated by scientific contacts. These contacts could take the form of having been students or colleagues at the same institution, or they could represent ties created through international science projects. The ties could also, as in the case of Okubo, be due to a scientist from abroad becoming established in another nation. The sorts of ties mentioned so far are really generic to all the sciences. What makes oceanography different is that the subject is inescapably international. The ocean is the common property of humanity, representing variously a boundary, a path for transportation and a source of wealth. None of these aspects of the ocean allows one nation to treat its oceanographic concerns in isolation from the rest of the world.

Since so many oceanographers have international ties, and since these ties are clearly important for doing the science, it may seem strange that internationally based oceanographic research can still be so hard to do. People who try to assemble international oceanography efforts have often run into a variety of obstacles. One is simply knowing who to talk to in another country about starting a project: it seems that, for many of us,

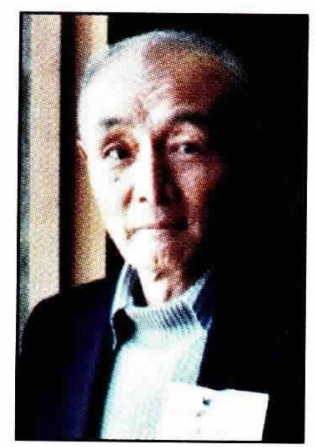

\section{Cover Photo:}

Akira Okubo at the Conference on Three Dimensional Animal Aggregations, held at the Monterey Bay Aquarium Research Institute, October 1991 (photo by Leah Edelstein-Keshet). our knowledge of another country's science community is not so complete as to make it easy to learn who to talk to. A second problem often encountered deals with funding: different nations have different funding procedures and different reasons for funding science. These organizational mismatches have been known to complicate scientific operations considerably despite the best intentions of all parties concerned.

Given that international ocean science can be difficult to organize, it is useful to remind ourselves of the reasons for taking this route. To an oceanographer, the most obvious reasons involve the science itself. Cooperations can lead to pooled resources that are increasingly needed in order to carry out expensive, global scale efforts. Further, cooperations can expedite access to unique locations, facilities or scientific talents that might otherwise be inaccessible to foreigners. Finally, doing international science in new settings with interesting people can just plain be fun.

International oceanography has benefits on a national level that transcend the science itself. In many cases, scientific cooperation can be used as a means to build communication and understanding between nations. Larger scientific projects will require serious attention to be paid by senior government officials who are willing to spend some time building international agreements.

Thus, ocean science fits into the international scene as a beneficiary of good relations between countries, and as a means to help meet the broader goals of a nation. In either case, the science itself, and the scientists, are in a position to benefit.

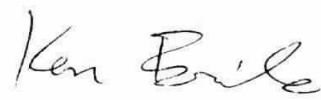

Books currently being reviewed for Oceanography:

People and the Earth: Basic Issues in the Sustainability of Resources and Environment By John J.W. Rogers and P. Geoffrey Feiss Published by Cambridge University Press

Ocean, Ice and Atmosphere: Interactions at the Antarctic Continental Margin Stanley Jacobs and Ray Weiss, Editors Published by The American Geophysical Union 